\title{
Comparative Study of Controllers for an Isolated Full Bridge Boost Converter Topology in Fuel Cell Applications
}

\author{
S. Vijaya Madhavi, G. Tulasi Ram Das \\ Department of Electrical and Electronics Engineering, JNTUH, Hyderabad, India
}

\begin{tabular}{l}
\hline \hline Article Info \\
\hline Article history: \\
Received Apr 16, 2018 \\
Revised Jul 17, 2018 \\
Accepted Jul 19, 2018 \\
\hline
\end{tabular}

\section{Keyword:}

Controllers

Fuel cells

Isolated full bridge boost

Converter

Renewable energy sources

\begin{abstract}
Now a day's renewable energy sources became an interesting area of research of which fuel cells are emerged as an alternative source for producing electricity to meet the energy crisis. This led to a research on power conditioning systems through which fuel cell is interfaced to the utility. Of the different converter topologies Isolated full bridge boost converter (IFBC) topology is most suitable for fuel cell applications. In this paper a Predictive Switching Modulator (PSM) Control is proposed for the converter topology and its performance is compared with Linear Peak Current Mode control (LPCM), Non-Linear Carrier Control (NLC).
\end{abstract}

Copyright $\odot 2018$ Institute of Advanced Engineering and Science. All rights reserved.

Corresponding Author:

S. Vijaya Madhavi,

Department of Electrical and Electronics Engineering,

JNTUH, Hyderabad, India.

Email : vijaya.madhavi83@gmail.com

\section{INTRODUCTION}

Now a day's renewable energy sources became an important area of research because of increase in energy demand, depletion of fossil fuel reserves, environmental pollution etc. Many alternative energy sources have been proposed in the literature of which fuel cells have emerged as a most efficient alternative energy source because of its advantages like refuel ability, producing very low emissions, portable in size, little maintenance etc. In spite of these benefits the price of fuel cell is its main constraint [1]-[2].

Fuel cell is an electro chemical device which gives electricity by combining hydrogen and oxygen without any combustion producing water and heat. These fuel cells show large change in output voltage under variable load conditions and also produce voltage very low in magnitude. To interface these fuel cells to utility loads or grid this low voltage must be raised to high value suitable for utility. Therefore high step up converters are required to interconnect fuel cells to utility loads.

Many models of DC-DC converters are mentioned in the previous survey papers which are acceptable for fuel cell applications. From the suggested topologies in the literature [3]-[5] Isolated Full Bridge Boost DC-DC converter topology is most efficient and acceptable for fuel cell applications. The main advantages of isolated full bridge topology are possibility of applying soft switching techniques, reasonable device voltage ratings, less transistor voltage and current stress, possibility of connecting devices in parallel to achieve desired power levels and high efficiency and galvanic isolation.

Under varying load and varying input voltage conditions DC-DC converters should provide regulated DC output voltage. Changes in time, temperature, pressure etc changes the values of the converter components. Applying of negative feedback in the form of a closed loop, regulation of DC voltage can be achieved. So the next task in designing a power conditioning system is developing a best controller meeting the requirements suitable for fuel cell applications. 
Basically there are two types of controllers, Voltage control and current control. Vast majority of DC-DC converters are implemented using current mode controllers because of its advantages [6]-[9]. Figure 1 shows the basic implementation diagram of current control.

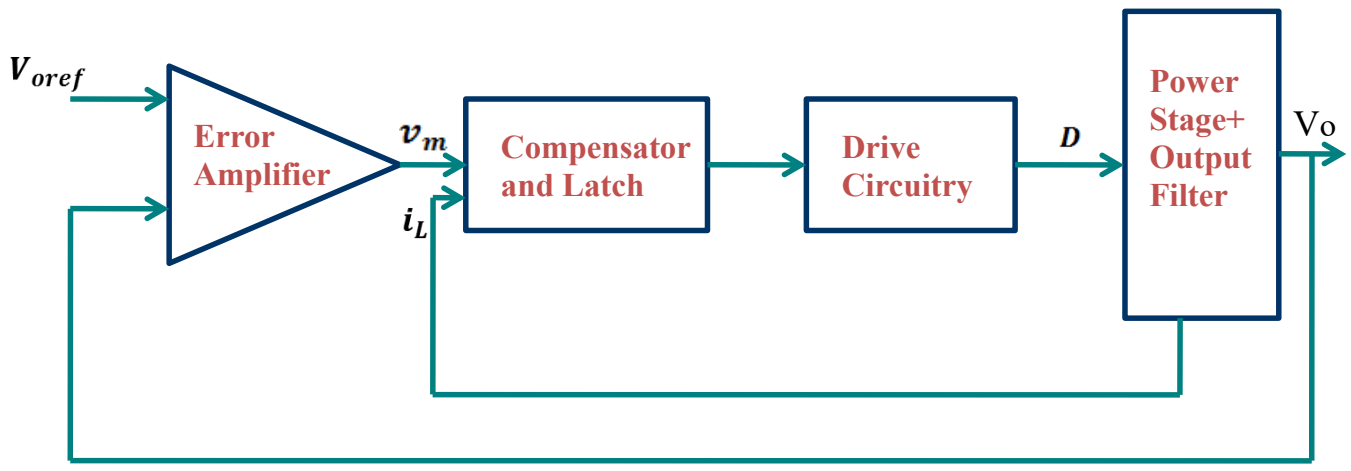

Figure 1. Block Diagram of Current Mode Control

Here the output stage is fed by the inductor current $i_{L}$ and the error voltage output from the error amplifier (known as control voltage) $v_{m}$ controls it. This has an extreme effect on a dynamic behaviour of the negative feedback control loop. Peak current control, average current control, non-linear carrier control are some of the techniques using this approach [10],[11].

In the linear peak current control (LPCM) peak switching current has to be sensed and therefore the sensing devices needed are more. In non-linear carrier current control (NLC) three reset integrators are needed to generate the carrier waveform. The NLC controlled converter results in distorted input current waveform in discontinuous conduction mode of operation.

To overcome the problems in LPCM and NLC controllers another control known as Predictive switching modulator control (PSM) [12],[13] is proposed where only two reset integrators are used when compared to NLC. Also PSM control extends the range of continuous conduction mode as prediction of off state ripple current is possible which is added to on state actual current at the end of switching period.

In this paper an isolated full bridge boost dc-dc converter topology is taken and first open loop configuration simulation is done using simulink. Next three types of controllers linear peak current mode control (LPCM), Non Linear Carrier control (NLC) and Predictive switching mode control (PSM) are applied to the converter topology. Finally the simulated results of all the three controllers are analysed and the proposed PSM control is compared with existing LPCM and NLC controllers.

\section{ISOLATED FULL BRIDGE BOOST CONVERTER TOPOLOGY (IFBC)}

\subsection{Basic Converter Operation}

In this section complete working of the converter is presented. Figure 2 shows the circuit diagram of the chosen converter topology and Figure 3 shows the performance of the converter according to the modes of operation.

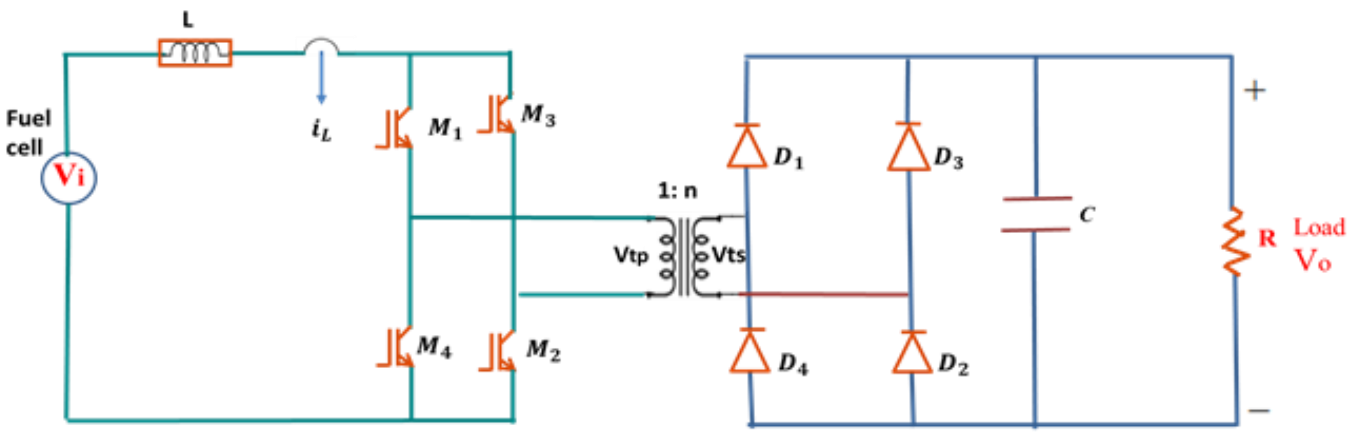

Figure 2. Circuit diagram of isolated Full Bridge Boost Converter Topology 


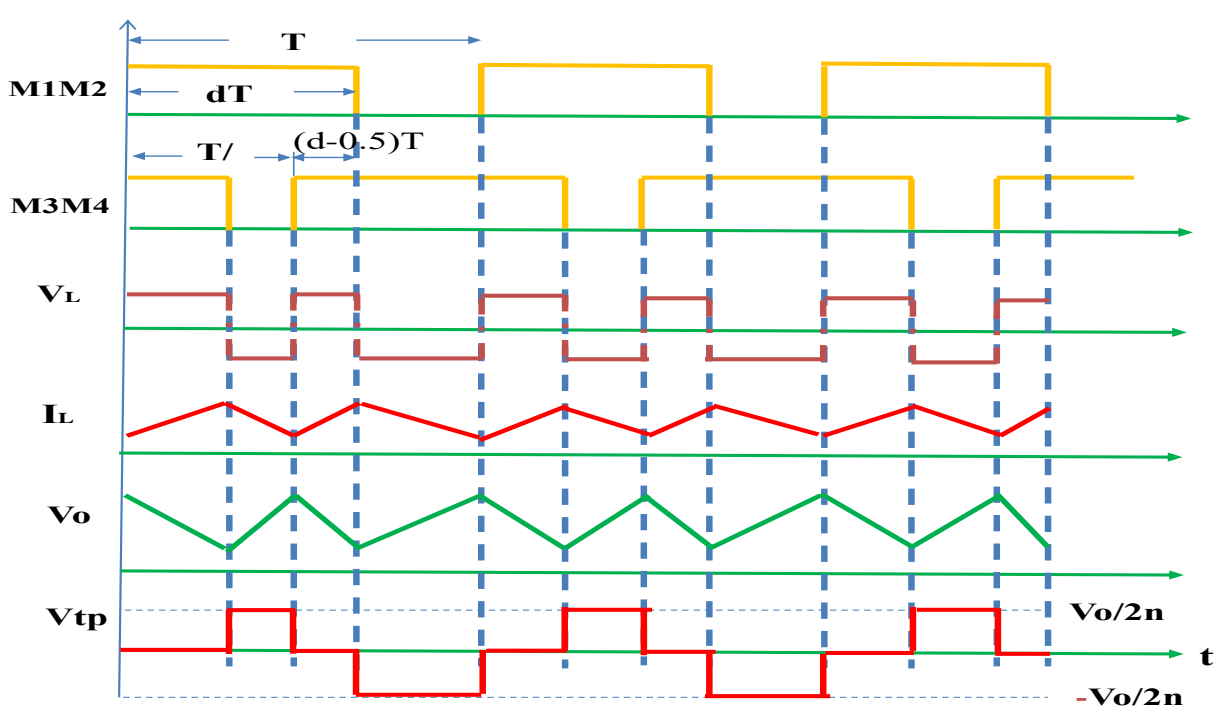

Figure 3. Basic operating waveforms of IFBC

The switches M1-M4 are run in pairs (i) M1-M2 and (ii) M3-M4 respectively. Switching pulses are 180 degrees phase shifted. Switch MOSFET duty cycle is chosen between 0.5 and 1 to ensure overlapping of switches.

Mode1: During this period energy starts to distribute. Switches M1-M4 are in conduction. Input inductor L is charged by input power and transformer secondary voltage is zero. Secondary diodes are all in off state.

Mode2: In this interval M1-M2 are in conduction and M3-M4 are in off state. Input power is allowed through M1-M2 and stored inductor energy is transferred to secondary side of transformer. Load power is achieved by conduction of diodes D1-D2.

Mode3: This mode is same as mode1. All switches are in conduction and source inductor current rises gradually.

Mode4: Reverse cycle period starts here. Switches M3-M4 are in conduction and M1-M2 are in off state. Discharging of source inductor energy and primary current transfer takes place through M3-M4 and transformer T1. Secondary current flow is achieved by conduction of diodes D3 and D4.

\subsection{Small Signal Modelling of IFBC Using Average State Space}

Many modelling techniques for the DC-DC converters are suggested in [14]-[18]. The converter can be modelled by state space averaging technique using following steps:

- Obtain state equations for each state (switch closed/open).

- Average the state equations in one switching period.

- The average equations thus obtained are perturbed thereby the variables have a DC and AC component.

- Next by applying Laplace Transform and excluding additional AC and DC terms (only the first order AC terms) the transfer functions needed can be achieved.

The modelled equations are simplified by taking some presumptions

- Ideal switches having no parasitic effect.

- No resistance for inductor

- Isolated transformer used is ideal and has no leakage, magnetizing inductance.

- Filter capacitor in output having less equivalent series resistance is assumed and it can be disregarded.

- Constant load

- Starting conditions are taken as zero at the time of operation.

\subsection{State Equations}

As seen in previous section operation of IFBC has two main intervals and their identical circuit diagrams are as shown in Figure 4. 


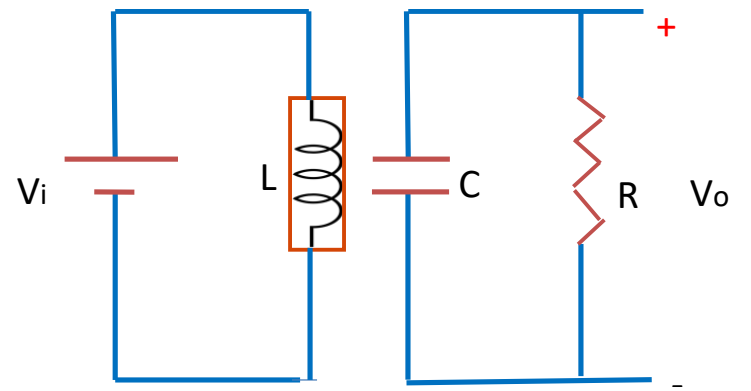

Interval 1

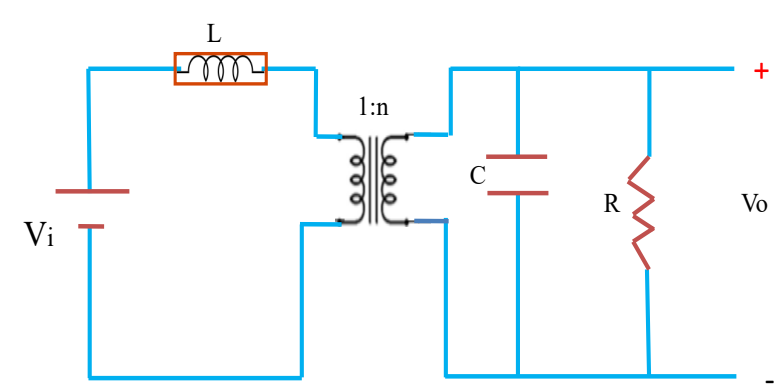

Interval 2

Figure 4. Equivalent circuit with all switches and two diagonal switches conducting

Interval 1: Here all the four switches M1-M4 conduct. The differential equations for this interval are written as below

$$
\begin{aligned}
& v_{i}=L \frac{d i_{L}}{d t} \stackrel{\text { yields }}{\longrightarrow} \frac{d i_{L}}{d t}=\frac{1}{L} v_{i} \\
& \frac{v_{O}}{R}+C \frac{d v_{O}}{d t}=0 \stackrel{\text { yields }}{\longrightarrow} \frac{d v_{O}}{d t}=\frac{-1}{R C} v_{O} \\
& {\left[\begin{array}{c}
\frac{d i_{L}}{d t} \\
\frac{d v_{o}}{d t}
\end{array}\right]=\left[\begin{array}{cc}
0 & 0 \\
0 & \frac{-1}{R C}
\end{array}\right]\left[\begin{array}{c}
i_{L} \\
v_{o}
\end{array}\right]+\left[\begin{array}{c}
\frac{1}{L} \\
0
\end{array}\right] v_{i}}
\end{aligned}
$$

This interval continues for $(\mathrm{d}-0.5) \mathrm{T}$ where $\mathrm{T}=1 / \mathrm{f}$ is the on period and $\mathrm{d}=t_{\text {on }} / T$ is the effectual duty ratio and $\mathrm{n}$ is the turns ratio of the isolated transformer.

Interval 2: In this the switches M1 and M2 are on. The differential relations of state variables for this interval are written as follows

$$
\begin{aligned}
& -v_{i}+L \frac{d i_{L}}{d t}+\frac{v_{O}}{n}=0 \stackrel{\text { yields }}{\longrightarrow} \frac{d i_{L}}{d t}=\frac{1}{L} v_{i}-\frac{1}{n L} v_{o} \\
& \frac{i_{L}}{n}=\frac{v_{O}}{R}+C \frac{d v_{O}}{d t} \stackrel{\text { yields }}{\longrightarrow} \frac{d v_{O}}{d t}=\frac{1}{n C} i_{L}-\frac{1}{R C} v_{o} \\
& {\left[\begin{array}{c}
\frac{d i_{L}}{d t} \\
\frac{d v_{O}}{d t}
\end{array}\right]=\left[\begin{array}{ll}
0 & \frac{-1}{n L} \\
\frac{1}{n C} & \frac{-1}{R C}
\end{array}\right]\left[\begin{array}{l}
i_{L} \\
v_{o}
\end{array}\right]+\left[\begin{array}{l}
\frac{1}{L} \\
0
\end{array}\right] v_{i}} \\
& \mathrm{Y}=v_{O}=Y_{o}=\left[\begin{array}{ll}
0 & 1
\end{array}\right]\left[\begin{array}{l}
i_{L} \\
v_{o}
\end{array}\right]+[0] v_{i}
\end{aligned}
$$

This interval continues for $(1-\mathrm{d}) \mathrm{T}$. The state equation for output in both the operations is same as (7). On averaging the state equations acquired during half of the switching cycle, a relation which has the features of both the modes is obtained

$$
\begin{aligned}
& \mathrm{A}=\left[\begin{array}{cc}
0 & \frac{-2(1-d)}{n L} \\
\frac{2(1-d)}{n c} & \frac{-1}{R C}
\end{array}\right] \quad B=\left[\begin{array}{l}
\frac{1}{L} \\
0
\end{array}\right] \\
& \dot{X}=\left[\begin{array}{cc}
0 & \frac{-2(1-d)}{n L} \\
\frac{2(1-d)}{n c} & \frac{-1}{R C}
\end{array}\right]\left[\begin{array}{l}
i_{L} \\
v_{o}
\end{array}\right]+\left[\begin{array}{l}
\frac{1}{L} \\
0
\end{array}\right] v_{i} \\
& Y_{O}=C X+D U=\left[\begin{array}{ll}
0 & 1
\end{array}\right]\left[\begin{array}{l}
i_{L} \\
v_{0}
\end{array}\right]+[0] v_{i}
\end{aligned}
$$


The state equations are perturbed about their operating points. The resulted relations are used for getting the necessary transfer functions

$$
\begin{aligned}
& \left\{\begin{array}{l}
i_{L}=I_{L}+\widehat{\iota_{L}} \\
v_{o}=V_{o}+\widehat{v_{o}} \\
v_{i}=V_{i}+\widehat{v_{l}} \\
d=D+\widehat{d} \\
v_{i}=V_{i}+\widehat{v_{l}}
\end{array}\right. \\
& \frac{d \widehat{l_{L}}}{d t}+\frac{d I_{L}}{d t}=\frac{2(D+\hat{d}-1)}{n L}\left(V_{o}+\widehat{v_{o}}\right)+\frac{1}{L} v_{i}=V_{i}+\widehat{v_{l}} \\
& \frac{d \widehat{v_{o}}}{d t}+\frac{d V_{o}}{d t}=\frac{2(1-D-\widehat{d})}{n C}\left(I_{L}+\widehat{\iota_{L}}\right)-\frac{1}{R C}\left(V_{o}+\widehat{v_{o}}\right) \\
& \frac{d \widehat{\iota_{L}}}{d t}=\frac{2(D+\widehat{d}-1)}{n L}\left(V_{o}+\widehat{v_{o}}\right)+\frac{1}{L} v_{i}=V_{i}+\widehat{v_{l}} \\
& \frac{d \widehat{v_{O}}}{d t}=\frac{2(1-D-\widehat{d})}{n C}\left(I_{L}+\widehat{\iota_{L}}\right)-\frac{1}{R C}\left(V_{o}+\widehat{v_{o}}\right)
\end{aligned}
$$

In matrix form the equations (14) and (15) are written as (16)

$$
\left[\begin{array}{c}
\frac{d \widehat{l}_{L}}{d t} \\
\frac{d \widehat{v}_{O}}{d t}
\end{array}\right]=\left[\begin{array}{cc}
0 & \frac{-2(1-D)}{n L} \\
\frac{2(1-D)}{n C} & -\frac{1}{R C}
\end{array}\right]\left[\begin{array}{l}
\widehat{\iota_{L}} \\
\widehat{v_{O}}
\end{array}\right]+\left[\begin{array}{l}
\frac{1}{L} \\
0
\end{array}\right]{\widehat{v_{l}}}+\left[\begin{array}{c}
\frac{2 V_{O}}{n L} \\
\frac{-2 I_{L}}{n C}
\end{array}\right] \hat{d}
$$

For obtaining transfer functions auxiliary AC and DC terms are avoided. The Laplace transform to the relations (14) and (15) is applied and the following transfer functions are obtained

$$
\begin{aligned}
& \frac{\widehat{\widehat{o}_{O}}}{\widehat{v_{l}}}=\frac{2(1-D) n}{n^{2} C L s^{2}+n^{2} \frac{L}{R} S+4(1-D)^{2}} \\
& \frac{\widehat{v_{O}}}{\widehat{d}}=\frac{-2 n L I_{L} S+8(1-D) V_{O}-2 n V_{i}}{n^{2} C L s^{2}+n^{2} \frac{L}{R} S+4(1-D)^{2}} \\
& \frac{\widehat{L}}{\widehat{d}}=\frac{2 n C V_{O} S+8(1-D) I_{L}}{n^{2} C L s^{2}+n^{2} \frac{L}{R} S+4(1-D)^{2}}
\end{aligned}
$$

Equation (18) is the control gain transfer function of IFBC and can be used for controlling of the converter.

\section{OPEN LOOP SIMULATION AND RESULTS}

The converter taken is constructed and simulated in MATLAB simulink in open loop configuration as in Figure 5. The design parameters of the topology are as given in Table 1. The output voltage of IFBC with and without load changes is as shown in Figure 6. 


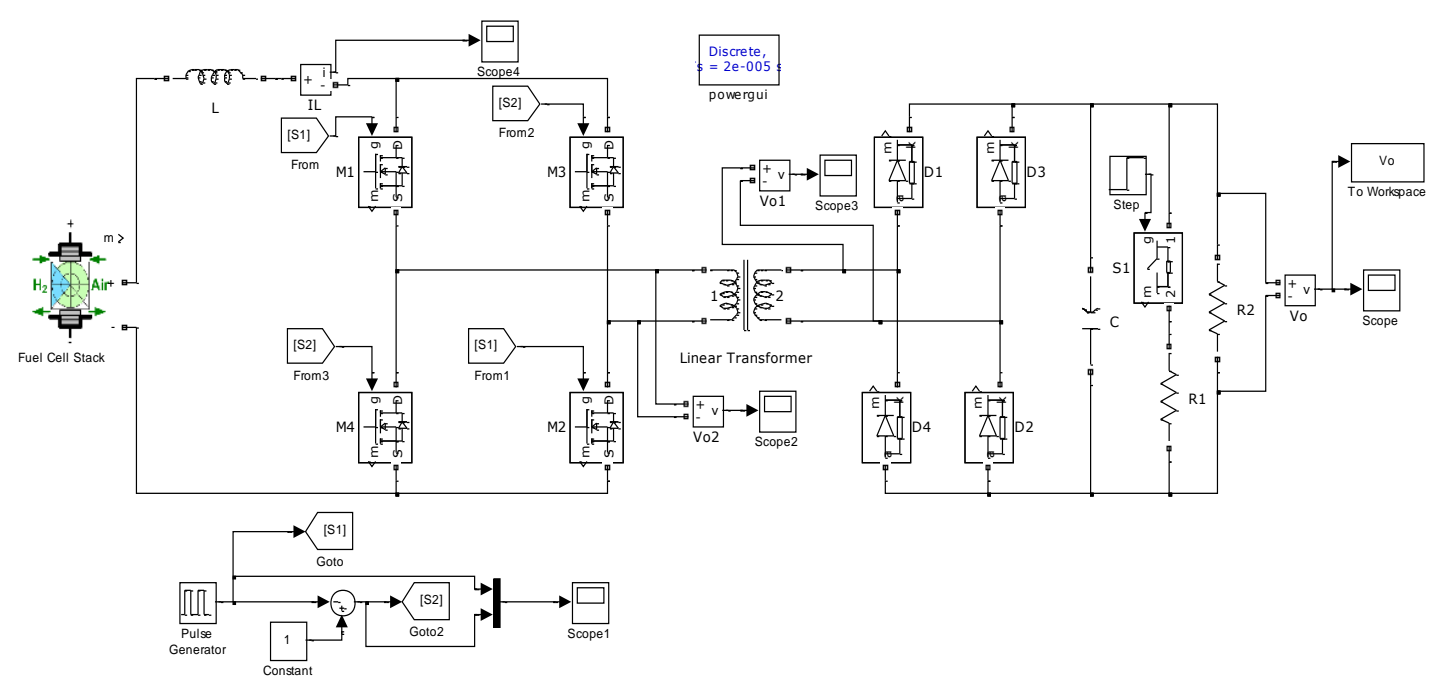

Figure 5. Simulink diagram of open loop configuration of the converter topology

Table 1. Design Specifications of IFBC

\begin{tabular}{cccc}
\hline Specification & Value & Specification & Value \\
\hline Output Power & $1 \mathrm{kw}$ & Output Capacitor C & $470 \mu \mathrm{F}$ \\
Input Fuel cell Voltage Vi & Fuel cell (6kw ,45V DC) & Load Resistor R & $400 \mathrm{ohms}$ \\
Output Capacitor Voltage Vo & $400 \mathrm{~V}$ & Transformer voltage turns ratio & $45: 400$ \\
Input Inductor L & $2.5 \mathrm{mH}$ & Switching frequency & $10 \mathrm{KHz}$ \\
\hline
\end{tabular}

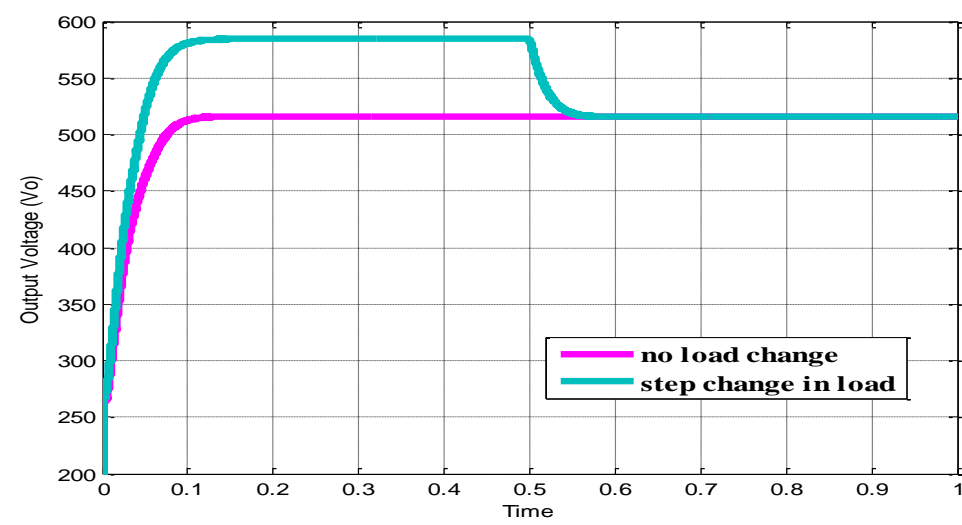

Figure 6. Output voltage of IFBC with and without load change

\section{IFBC WITH LPCM AND NLC CONTROLLERS}

\subsection{Operation of LPCM and NLC Control Topology}

These types of controllers are based on current control mode theory. In this control mainly the inductor is transformed into a current source thereby removing the inductor performance in the loop. A set value for current is provided by the controller and the loop inside follows this value in each cycle and hence this control can also be called as one cycle control. Why this control is called as linear peak current control because, the peak value of the inductor current obeys the set value and the linear relation between the current and off duty cycle ratio. Generally this control has two loops. One is the voltage loop outside which has an error amplifier that counteracts the dynamic response of the output voltage and second is a current loop inside that gives compact control on peak inductor current. Sensing of output voltage in this technique can be from a feedback network and the two voltages (reference and output) are compared in a comparator for obtaining the control voltage. The feedback network impedance is much greater than that of the load. Then the inductor current sensed and the control voltage are compared in the modulator to calculate the duty ratio which is then changed to output voltage by the power stage. 
Inherent sub harmonic oscillations lead to stability problem when the duty ratio of the switches crosses $50 \%$ and noise susceptibility. This can soon reset the latch; interrupt the performance of the controller. Therefore the sensed switch current waveform is needed to be filtered by little amount so that the turn on current spike can be discarded which is effected by the diode stored charge. To overcome this adding an substitute ramp for the controller makes better the noise immunity of the circuit. So generally to keep away from the instability problem, the control scheme is altered by addition of an artificial ramp to the sensed inductor current waveform [19]-[21] but the result is it increases circuit complexity.

So to make the control scheme easy an approach known as quasi-steady-state is generally used. With this technique, a simple equation is solved in the modulator and thereby the duty ratio of switch is obtained. The equation consists of the sensed current (i.e. the switch current average for the NLC) on one side and opposite side is carrier wave obtained by computing the result of voltage regulator.

The main difference between NLC and LPCM controllers is by producing a proper carrier, the NLC controller executes average current control in contrast the peak current controller produces a distinct wave in order to apply the actual concept of peak current mode control. Figure 7 shows the Schematic form of representation of the LPCM and NLC controllers.

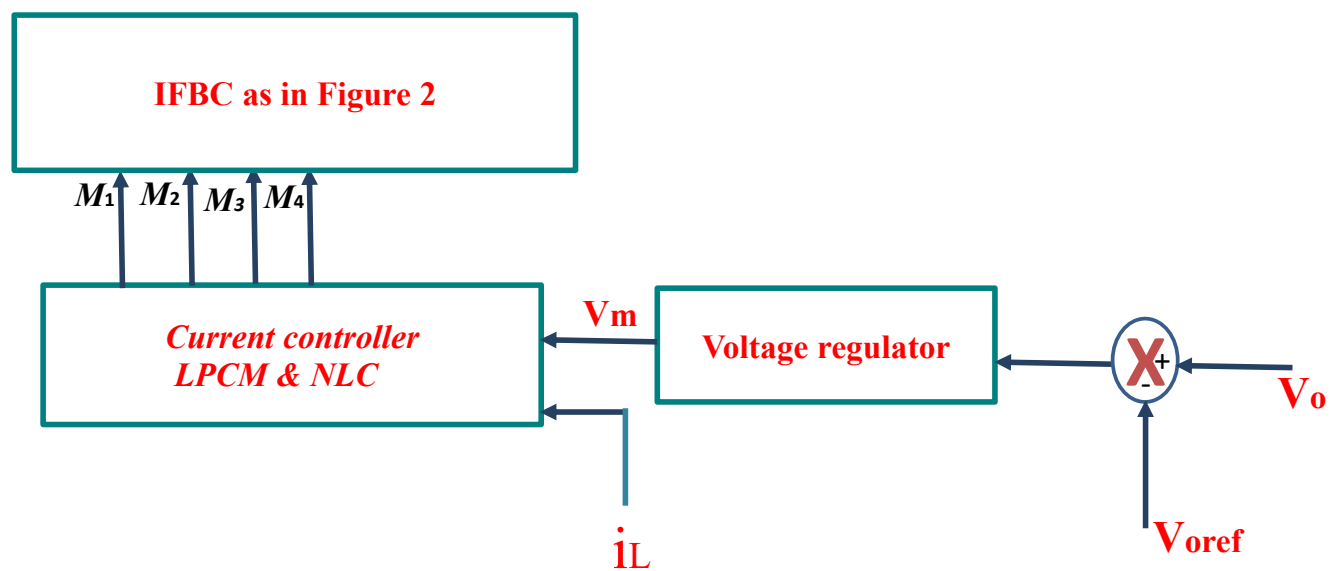

Figure 7. Block diagram of LPCM and NLC controllers

The non-linear carrier control applies average current mode control. Therefore the generalised control objective for NLC is

$$
f\left(i_{L}\right)_{N L C}=i_{L, \operatorname{avg}(T)}=\frac{1}{T} \int_{0}^{T} i_{L} d t
$$

And in LPCM the function is

$$
f\left(i_{L}\right)_{L P C M}=i_{L p}=i_{L}(d T)
$$

where $i_{L p}$ is peak inductor current. This current in one switching period goes to its peak at when the switch reaches to the end of on time $\mathrm{d} T_{S}$.

\subsection{LPCM Controller and Carrier Generation Blocks in Simulink}

This section shows how LPCM controller is built and how the carrier is generated in MATLAB. The simulink blocks built in MATLAB are as as shown in Figures (8) and (9) respectively. 


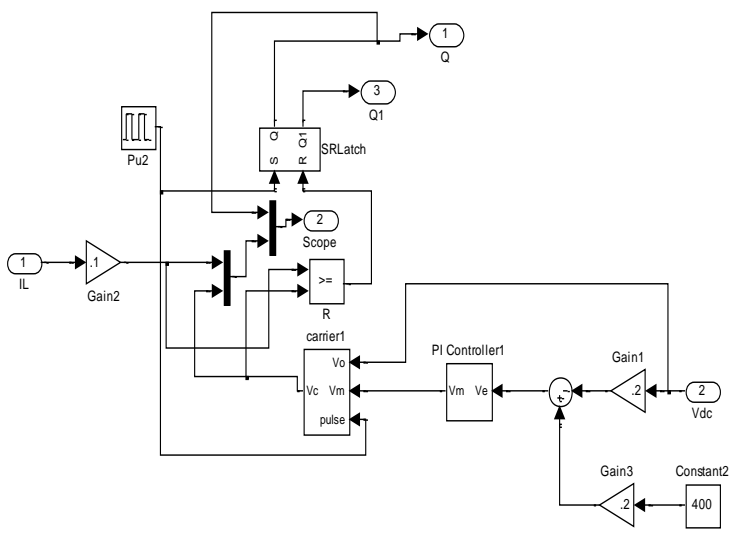

Figure 8. Simulink Block of LPCM

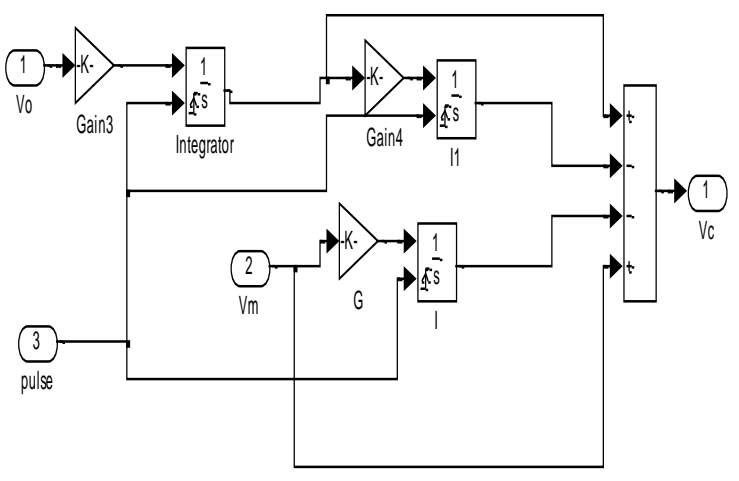

Figure 9. Simulink carrier block of LPCM

\subsection{NLC Controller Block and Carrier Generation in Simulink}

In this section NLC controller block and its carrier generation are build in MATLAB Simulink software and are as shown in Figures (10) and (11) respectively

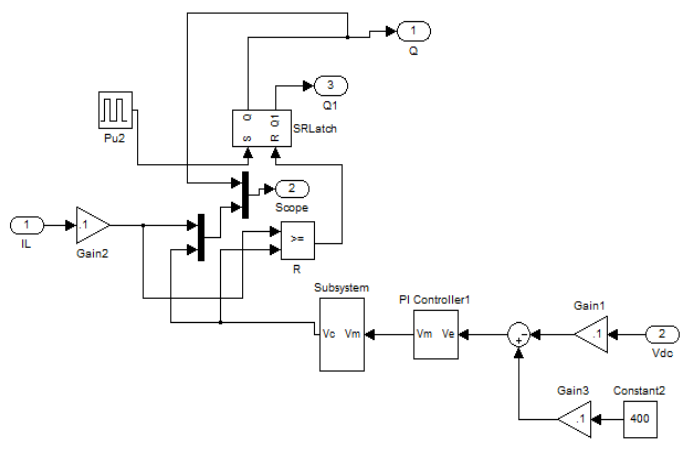

Figure 10. Simulink Block of NLC Controller

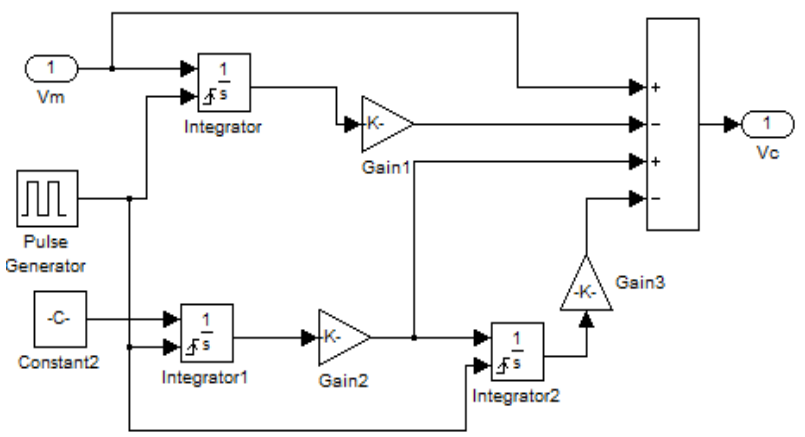

Figure 11. Simulink carrier block of NLC

\section{IFBC WITH PREDICTIVE SWITCHING MODULATOR CONTROL (PSM)}

\subsection{Operation Of Psm Control Topology}

This control topology is mentioned in [22]. Inductor current evaluated is made proportional to the input voltage at the end of the switching period $(\mathrm{T})$ by controlling the switch duty ratio. Over a period of switching the inductor current evaluation is feasible as the input voltage is nearly sustained. Therefore estimation of ripple current in the subsequent off period throughout the switch on time is possible. Now to control to the current the estimated off state ripple current is added with the on state actual current at the end of the switching period. Figure 12 shows schematic form of operation of PSM control. 


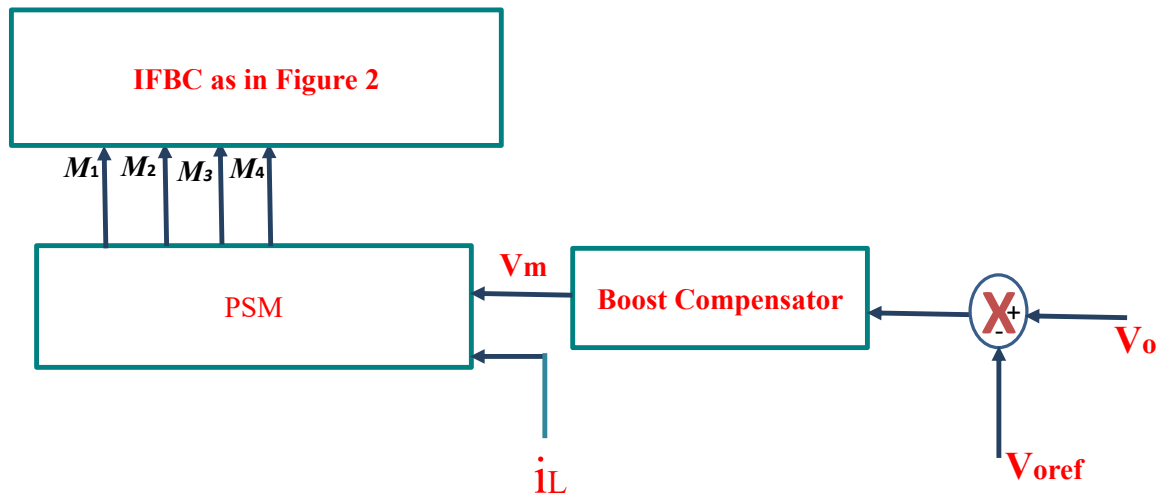

Figure 12. Block Diagram of PSM Control

The first objective i.e. attaining the control gain transfer function of the IFBC was done in section 2.2 and is given by equation (18).

\subsection{Low Frequency Small Signal Model of the Converter for PSM}

Here to derive the model, variables are indicated by capital letters (nominal as well as DC) and small-signal variations are shown by $(\wedge)$ above the symbol. The control formation of the current mode controller is as shown in Figure 13.

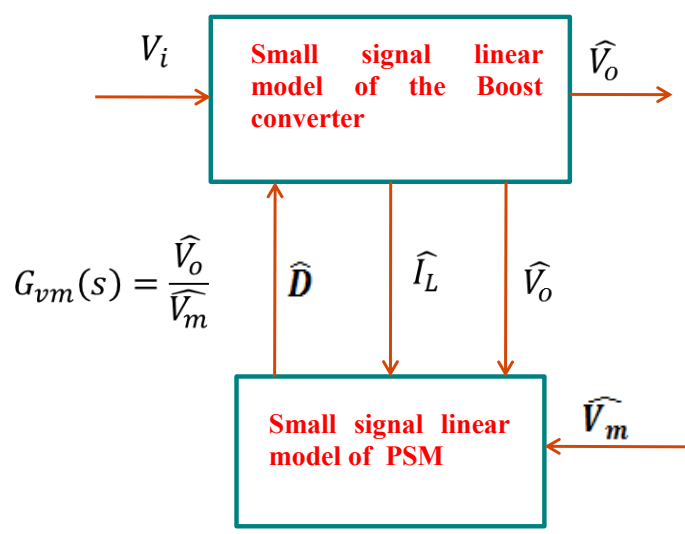

Figure 13. Control structure of PSM controller

First the converter model is derived in normal forms with reference to perturbations of duty ratio. The modulator small signal model is acquired eventually in and substitute $\widehat{D}$ by the perturbations in error amplifier output voltage $\widehat{V_{m}}$ and other state variables $\widehat{V}_{o}$ and $\widehat{l_{L}}$. The relations of state space average model of the IFBC are given by (16).

The duty ratio of the period is produced by using the inductor current $i_{L}$ and the output voltage $V_{o}$ in the modulator according to

$$
V_{m}(1-D)+\frac{V_{o} R_{S} T}{n L} D-\frac{V_{o} R_{S} T}{n L} D^{2}=I_{L} R_{S}+\frac{V_{i} R_{S} T}{2 n L} D
$$

where $R_{s}$ is the resistance from which the inductor current is sensed. The steady state duty ratio can be derived (is the positive real root and less than 1) by solving equation (13).It can be developed by using equation (12) and the equations

$$
\begin{aligned}
& V_{i}=(1-\mathrm{d}) V_{o} \text { and } R_{S}\left\langle i_{L}\right\rangle=\frac{V_{m} V_{i}}{V_{o}} \\
& {\left[-V_{m}+\frac{V_{i} R_{S} T}{2 n L}\right] D^{3}+\left[3 V_{m}+\frac{V_{i} R_{S} T}{n L}\right] D^{2}+\left[-3 V_{m}+\frac{V_{i} R_{S} T}{n L}\right] D+\left[V_{m}-\frac{V_{i} R_{S}}{R}\right]=0}
\end{aligned}
$$


Perturbing equation (23) and linearizing the quantities subsequently i.e. $\mathrm{D}=\mathrm{D}+\widehat{D}, V_{m}=V_{m}+\widehat{V_{m}}, V_{o}=V_{o}+$ $\widehat{V_{o}}$ and $i_{L}=i_{L}+\widehat{\imath_{L}}$ to derive small signal model of PSM as shown below

$$
\left[V_{m}+\frac{V_{i} R_{S} T}{2 n L}+2 D V_{o}\left(\frac{R_{S} T}{n L}\right)-V_{o}\left(\frac{R_{S} T}{n L}\right)\right] \widehat{D}=(1-D) V_{m}+\widehat{D(1-D)} \widehat{V}_{o}\left(\frac{R_{S} T}{n L}\right)-\widehat{I}_{L} \widehat{R}_{S}
$$

Let us define a constant $\mathrm{N}$ as follows

$$
N=\left[\frac{V_{m}}{V_{m o}}+\frac{V_{i} R_{S} T}{2 n L V_{o}}+2 D\left(\frac{R_{S} T}{n L}\right)-\left(\frac{R_{S} T}{n L}\right)\right]
$$

Rewriting (16) as (26) and by replacing the expression of (24) by using definition of $\mathrm{N}$ we get

$$
\left[\begin{array}{l}
\frac{d \widehat{I}_{L}}{d t} \\
\frac{d \widehat{V}_{O}}{d t}
\end{array}\right]=\left[\begin{array}{cc}
\frac{-R_{S}}{n L N} & \frac{-(1-D)}{n L}+\frac{D(1-D) R_{S} T_{S}}{N T} \\
\frac{(1-D)}{n C}+\frac{I_{L} R_{S}}{n C V_{O} N} & \frac{-1}{R C}-\frac{I_{L} D(1-D) R_{S} T_{S}}{n^{2} C V_{O} N L}
\end{array}\right]\left[\begin{array}{c}
\widehat{I}_{L} \\
\widehat{V_{o}}
\end{array}\right]+\left[\begin{array}{c}
\frac{(1-D)}{n L N} \\
\frac{-I_{L}(1-D)}{n C V_{O} N}
\end{array}\right] \widehat{V_{m}}
$$

Ultimately the control gain transfer function of PSM is obtained as follow

$$
G_{V m}(s)=\frac{\widehat{V_{O}}}{\widehat{V_{m}}}=\frac{-\left[\frac{s}{Z R S} \frac{4(1-D)^{2}}{n^{2} N C L}\right]}{s^{2}+s\left[\frac{1}{R C}+\frac{D R_{S} T_{S}}{n^{2} N R C L}+\frac{R_{S}}{n N L}\right]+\left[\left(\frac{4(1-D)^{2}}{n^{2} L C}\right)\left\{1-\frac{D R_{S} T_{S}}{n N L}\right\}+\left\{\frac{2 R_{S}}{n^{2} N R L C}\right\}\right]}
$$

The systematic model which is acquired is justifiable only at input - output and load condition when the IFBC continues to operate in continuous conduction mode. At last a closed loop controller can now be constructed for the outer voltage loop depending on the control transfer function given by equation (27) by using the normal method mentioned in linear control theory. Now the frequency response of the voltage error amplifier can be drawn by using this.

\subsection{Boost Compensator Design in PSM Control}

Now in this section a closed loop boost compensator can be constructed depending on the model given by equation (27). The schematic form is shown in Figure 14.

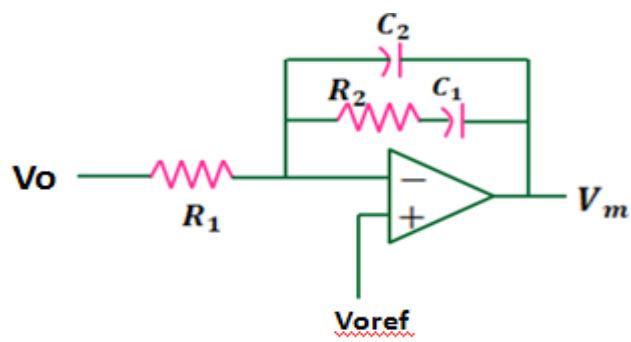

Figure 14. Block Diagram of Boost Compensator

The transfer function of the boost compensator is given by equation (18)

$$
G_{B}(S)=\frac{A}{S} \frac{S+w_{Z}}{S+w_{p}}
$$

where

$$
A=\frac{1}{R_{1} C_{1}}, w_{z}=\frac{1}{R_{2} C_{1}}, w_{p}=\frac{C_{1}+C_{2}}{R_{2} C_{2} C_{1}}
$$

where $\mathrm{A}$ is positive and $w_{z}<w_{p}$. As there is a pole at the origin, the phase of $G_{B}(s)$ starts with $-90^{\circ}$. The existence of the zero yields a "boost" to be something greater than $-90^{\circ}$. Finally he pole at $w_{p}$ causes the phase angle of $G_{B}(s)$ to come back down to $-90^{\circ}$. 


\subsection{Designing of Boost Compensator}

The specifications in equation (18) can be designed using K-factor approach [23]-[25]. The step by step design process of the suggested closed loop boost compensator PSM controller is described as below.

STEP 1: Find out the cross over frequency $w_{\text {cross }}$. The K-factor is utilised such that

$$
\begin{aligned}
& w_{z}=\frac{w_{\text {cross }}}{K} \\
& w_{p}=K w_{\text {cross }}
\end{aligned}
$$

$\mathrm{K}$ can be defined as

$$
K=\tan \left(45^{\circ}+\frac{\text { boost }}{2}\right)
$$

STEP 2: The needed closed loop PM at the cross over frequency is fixed and hence the boost needed from the error amplifier to calculate $\mathrm{K}$ in equation (29) and (30).. Boost can be outlined as

$$
\text { Boost }=\mathrm{PM}-\varphi_{1}-90^{0}
$$

where $\varphi_{1}$ is the phase angle of loop transfer function $G_{V m}(s)$ at the cross over frequency. It can be derived from the frequency response of the equation (27).

STEP 3: Obtain the gain $G_{C I F B}(s)$ of the compensator at $w_{\text {cross }}$ by using the condition

$$
\left|G_{v m}\left(w_{\text {cross }}\right)\right|=1
$$

STEP 4: The value of $R_{1}$ is set. From equations (28) to (33) rest of the parameters can be calculated as follows

$$
\begin{aligned}
C_{2} & =\frac{G_{1}}{K R_{1} w_{\text {cross }}} \\
C_{1} & =C_{2}\left(K^{2}-1\right) \\
R_{2} & =\frac{K}{C_{1} w_{\text {cross }}}
\end{aligned}
$$

From equation (27) and (28) the loop transfer function $G_{I F B B}(s)=G_{v m}(s) G_{B}(s)$ of IFBC with boost compensator is calculated.

\subsection{PSM SIMULINK AND GENERATION OF CARRIER BLOCKS IN SIMULINK}

Here using PSM principle as explained in previous section, the controller is generated in MATLAB Simulink software as shown in Figure (15). Later the carrier for control is generated in the same software as shown in Figure (16).

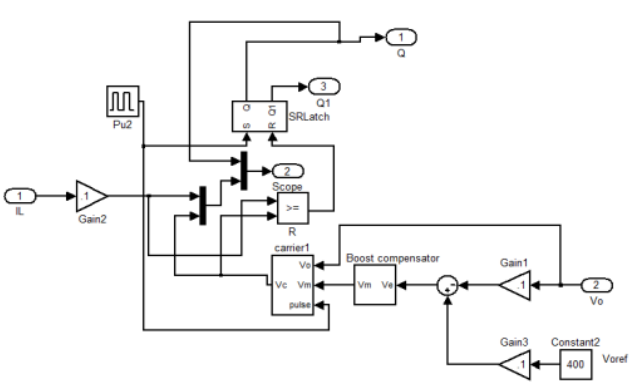

Figure 15. Simulink Block of PSM

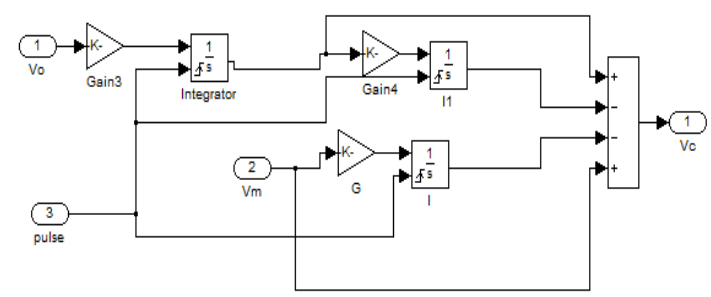

Figure 16. Simulink Carrier Block of PSM 


\section{SIMULATION RESULTS WITH CONTROLLERS}

The open loop IFBC constructed is simulated in MATLAB simulink applying three controllers. Figure 17 shows the output voltage of the converter with the controllers for step change of load.

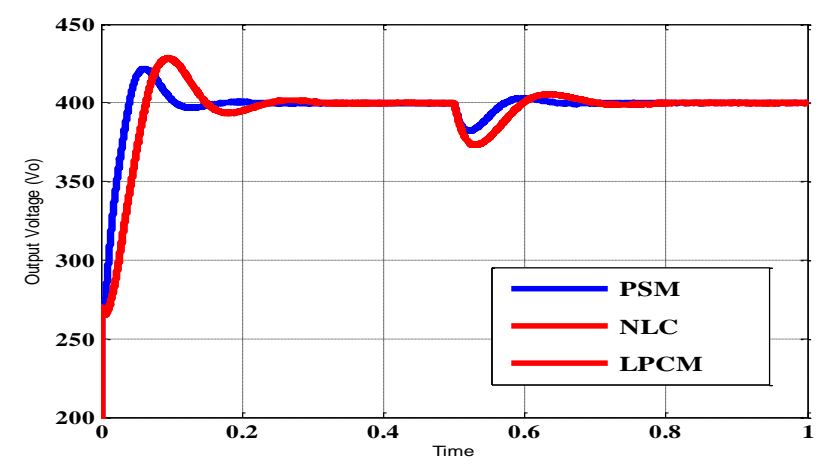

Figure 17. Output voltage of IFBC with LPCM NLC and PSM controllers with step change in load

\section{COMPARISON OF LPCM, NLC AND PSM CONTROLLERS}

From the simulation results obtained as shown in Figure 17 the comparative Table 2 shows the performance analysis of the IFBC converter topology with LPCM, NLC and PSM controllers. It shows that PSM controller gives better transient response and steady state stability.

Table 2. Performance of IFBC Controllers

\begin{tabular}{ccccc}
\hline $\begin{array}{c}\text { Controlling } \\
\text { Scheme }\end{array}$ & $\begin{array}{c}\text { Rise Time } \\
(\text { tr sec })\end{array}$ & $\begin{array}{c}\text { \%Peak Over } \\
\text { shoot }(\mathrm{Mp})\end{array}$ & $\begin{array}{c}\text { Settling Time } \\
(\mathrm{Ts})\end{array}$ & $\begin{array}{c}\text { Steady State } \\
\text { Error }\left(e_{S S}\right)\end{array}$ \\
\hline PSM & $<0.05$ & $<5$ & $<0.2$ & 0 \\
NLC & $<0.1$ & $<8$ & $<0.4$ & 0 \\
LPCM & $<0.1$ & $<7.5$ & $<0.4$ & 0 \\
\hline
\end{tabular}

\section{CONCLUSION}

In this paper an Isolated Full Bridge Boost Converter used for fuel cell applications was presented and implemented in closed loop configuration. The detailed modelling of the converter topology was also presented. The IFBC topology was constructed for three types of controllers i.e. LPCM, NLC and PSM and comparison of the three controllers was observed and presented. The obtained results show that the proposed PSM controller gives good transient and steady state stability performance compared to LPCM and NLC controllers as the peak overshoot, rise time and settling time of PSM are reduced during load changes. Further the PSM controller extends the continuous conduction mode of converter which will reduce the size of EMI and the problem of using three integrators in NLC is also eliminated by using only two in PSM.

\section{REFERENCES}

[1] A. N. Mishra, et al., "Opportunities and Challenges for Fuel Cells in India," International journal of Advanced Research in Science and Engineering, vol/issue: 5(6), 2016.

[2] V. Das, et al., "Recent advances and challenges of fuel cell based power system architectures and control - A review," Renewable and Sustainable Energy Reviews, vol. 73, pp. 10-18, 2017.

[3] A. Emadi, et al., "Power electronics intensive solutions for advanced electric, hybrid electric, and fuel cell vehicular power systems," IEEE Trans. on Power Electronics, pp. 567-577, 2006.

[4] A. Emadi, et al., "Topological overview of hybrid electric and fuel cell vehicular power system architectures and configurations," IEEE Trans. on Vehicular Technology, pp. 763-770, 2005.

[5] A. Averberg, et al., "A Survey of Converter Topologies for Fuel Cells in the kW Range," Energy 2030 Conference, ENERGY 2008, IEEE, 2008.

[6] K. Rajashekhara, "Power conversion and control strategies for fuel cell vehicles," Proc. IEEE IECON, 2003.

[7] X. Kong, et al., "Analysis and control of isolated current-fed full bridge converter in fuel cell system," Proc. IEEE IECON, vol. 3, pp. 2825-2830, 2004.

[8] S. Dhanasekaran, et al., "Different Methods of Control Mode in Switch Mode Power Supply- A Comparison," International Journal of Advanced Research in Electrical, Electronics and Instrumentation Engineering, vol/issue: 3(1), 2014.

Comparative Study of Controllers for an Isolated Full Bridge Boost Converter.... (S. Vijaya Madhavi) 
[9] S. Selvaraj, at al., "Optimization and Closed Loop Control of Soft Switched Boost Converter with Flyback Snubber," International Journal of Computer Applications (0975 - 8887) International Conference on Innovations in Intelligent Instrumentation, Optimization and Signal Processing ICIIIOSP, 2013.

[10] L. N. Rao, et al., "Design of DC-DC Boost Converter with Negative Feedback Control for Constant Current Operation," International Journal of Power Electronics and Drive System (IJPEDS), vol/issue: 8(4), pp. 1575 1584, 2017.

[11] G. S. Rao, et al., "Design of Feedback Controller for Boost Converter Using Optimization Technique," International Journal of Power Electronics and Drive System (IJPEDS), vol/issue: 3(1), pp. 117 128, 2013.

[12] Santhosh T. K. and Govindaraju C., "Development of Predictive Current Controller for Multi-Port DC/DC Converter," International Journal of Power Electronics and Drive Systems (IJPEDS), vol/issue: 6(4), pp. 683 692, 2015.

[13] Y. Massaoudi, et al., "Comparison between non linear controllers applied to a DC-DC boost converter," International Journal of Innovative Computing, Information \& Control, vol/issue: 11(3), pp. 935-947, 2015.

[14] J. Zhang, et al., "Bidirectional DC-DC converter modelling and unified controller with digital implementation," Applied Power Electronics Conference and Exposition, Twenty-Third Annual IEEE, pp. 1747 - 1753, 2008.

[15] A. Emadi, "Modeling and analysis of multiconverter DC power electronic systems using the generalized state-space averaging method," Industrial Electronics, IEEE Transactions on, vol/issue: 51(3), pp. 661- 668, 2004.

[16] H. Y. Cho and E. Santi, "Modeling and stability analysis in multiconverter systems including positive feedforward control," IEEE IECON Conference, pp. 839-844, 2008.

[17] B. Zahedi and L. E. Norum, "Modeling, Analysis and Control of an Isolated Boost Converter for System Level Studies," Aegean Conference on Electric Machines and Power Electronics, 2011.

[18] R. W. Erickson, "Fundamentals of Power Electronics," Kluwer Academic Publishers, 1999.

[19] R. Zane and D. Maksimovic, "Nonlinear carrier control for high-power-factor rectifier based on up-down switching converters," IEEE Trans. Power electron., vol. 13, pp. 213- 221, 1998.

[20] S. Amir, et al., "Improved Modeling and Analysis Technique for Peak Current Mode Control based Boost Converters."

[21] R. Sheehan, et al., "Practical Design Guide for Fixed-Frequency, Continuous Conduction-Mode Operation," Understanding and Applying Current-Mode Control Theory.

[22] S. Chattopadhyay, et al., "A Predictive Switching Modulator for Current Mode Control of High Power Factor Boost Rectifier," IEEE Transactions on Power Electronics, vol/issue: 18(1), 2003.

[23] H. D. Venable, "The K-Factor; A new mathematical tool for stability analysis and synthesis," Proceeding of powercon 10, Sam Diego, CA, 1983.

[24] K. R. Prasad, et al., "Boost Compensator for Predictive Current Mode Control of High Power Factor Boost Rectifier," International journal of computer applications, vol/issue: 5(2), 2010.

[25] N. Mohan, et al., "Power Electronics Converters, Applications and Design," John Wiley \& Sons (Asia) Pte Ltd. Second Edition, 1995.

\section{BIOGRAPHIES OF AUTHORS}

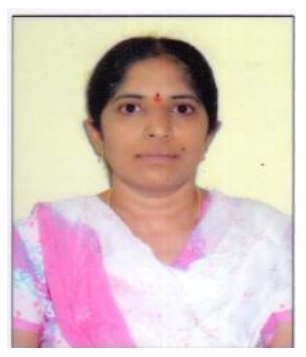

S.Vijaya Madhavi was born in India. She received her B.tech in the department of EEE (2005), from PVP Siddhartha Institute of Technology, Vijayawada India and M.tech (2007) in department of EEE, from Jawaharlal technological university Hyderabad. She has five years of teaching experience in JNTU affiliated colleges. Presently she is pursuing her PhD in department of EEE, Jawaharlal technological university Hyderabad. Her research interests include power electronic converters, renewable energy sources and controlling of SMPS.

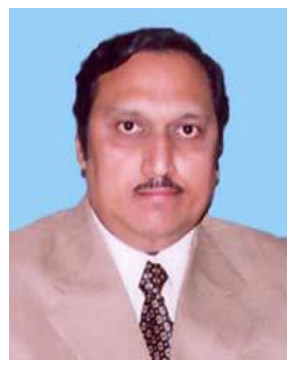

Dr. G Tulasi Ram Das was born in the year 1960 in Hyderabad, Andhra Pradesh, India. He received his B.Tech, in Electrical \& Electronics Engineering from JNT University Hyderabad in 1983 and M.E., in Industrial Drives and Controls from Osmania University, Hyderabad in 1986 and Ph.D., in Electrical Engineering from Indian Institute Of Technology, Madras in 1996. He was Vice-Chancellor, for JNTUK Kakinada, from Nov2011 to Nov2014. Presently he is Professor in department of EEE, JNT University Hyderabad. His research interests include Power Electronics, Power Semi-conductor controlled electric drives (IM, PMSM, \& BLDCM), Resonant Converters, Multilevel Converters, Flexible AC Transmission Systems (FACTS), Power Quality and Solar PV Cell Technologies, and E-waste management. He has published 151 Research papers in Electrical Engineering at National and International Journals and Conferences. He is a member in editorial board of three journals. 